\title{
An Analysis of the Perplexity and Path of Parent-Child Book Reading for Preschool Children in Top Classes
}

\author{
Liu Li ${ }^{1, *}$, Yang Cenxi ${ }^{1}$ \\ ${ }^{1}$ School of Preschool Education, Chongqing university of education, Chongqing 400065, China \\ *Corresponding author Email: liul@cque.edu.cn
}

\begin{abstract}
Parent-child book reading, as one of the important ways of early reading in family education, has been highly valued by parents under the development of the nationwide reading activities advocated in the new era. Children in top classes are at an important stage of the transition from kindergarten to primary school. The book reading activities that parents participate in can help children to develop reading habits, bring artistic edification and establish good parent-child relationships. Through the questionnaire survey method, this paper deeply investigates and analyzes the participation of the parents of preschool children in top classes of three kindergartens in a certain urban area in book reading activities for preschool children in top classes. Based on this, exploring the perplexity and path of parent-child book reading for preschool children in top classes.
\end{abstract}

Keywords: Book reading; Parent-child reading; Family education

and other reading activities. From the perspective of parent-child book reading for preschool children in top

\section{INTRODUCTION}

Under the trend of life-long education and nationwide reading, many countries in the world are paying attention to the theory and practice of children book reading, and have achieved certain results ${ }^{[1,2]}$. Undoubtedly, China is one of the member of this team, and it has introduced documents and policies from a macro level to encourage all the people to participate in reading. The Outline of Educational Guidance in Kindergartens (Trial) promulgated by the Ministry of Education in 2001 pointed out that "Cultivating children's interest in simple signs and letter symbols that are common in life, and using books, paintings and other methods to trigger children's interests in books, reading and writing are necessary" ${ }^{[3]}$. In addition, the Early Learning and Development Guideline at 3-6 Years Old promulgated by the Ministry of Education in 2012 also clearly stated that "in the field of language, children's reading and writing skills should be developed, and there are three objectives should be completed: One is to cultivate children's interest in listening to stories and reading books; the second is to let children own the ability of preliminary reading comprehension; and the third is to let children have the desire to write and preliminary skills." ${ }^{[4]}$ It is not difficult to conclude that reading is indispensable for children in language learning and verbal learning ${ }^{[5,6]}$. While picture books are one of the learning tools that play an important role in children's learning and reading.

\section{RESEARCH PROCESS AND FINDINGS}

With the promotion and development of picture book reading, many kindergartens have launched classroom picture book reading teaching, parent-child book reading classes, this research selected three kindergartens that had carried out picture book reading activities in a certain urban area to implement a questionnaire survey. We distributed 163 questionnaires to some parents of top classes but withdrew 156 questionnaires. The recovery rate was $95.71 \%$. In the retracted questionnaires, 152 questionnaires were valid, and the effective recovery rate was $93.25 \%$. This questionnaire has 23 questions totally, including 19 single choice questions, 3 multiple choice questions, and 1 open-ended question. The questionnaire includes four dimensions: parent-child book reading cognition, parent-child book reading time and frequency, parent-child book reading instruction method, and parent-child book reading selection basis.

There are some findings. Firstly, most parents have a positive attitude towards picture book reading, which is reflected in the increase in understanding, the popularity of using, the clarity of participation behavior, and the improvement of attention. But they lack scientific understanding and simply regard the reading of picture books for preschool children in top classes as a "primary school transition bridge". Secondly, in terms of the selection of picture books, most parents prefer the picture books with educational significance and aesthetic colors. Besides, some parents prefer the practical picture books, and regard the quality and price of the books as the factors for choosing picture books. However, there is a lack of choices for considering picture books from the perspectives of the laws of the childrens' physical and mental development, the laws of education itself, and the interests of children. Thirdly, the degree of emphasis of parents on the duration and frequency of children's picture book reading activities has greatly increased, but they still fail to put their consciousness into action, and they cannot reasonably arrange the time and frequency of picture book reading. It is difficult to determine a stable parent-child reading behavior between parents and children. There lack 
scientific plans for the the time of parent-child book reading. Fourth, in the guidance of parent-child book reading, parents prefer to reading while communicating with their children. At the same time, some parents pay attention to the questions and answers of preschool children in top classes and are willing to satisfy the strong desire for knowledge of children at this stage. However, the lack of scientific guidance methods for reading the picture books cannot maximize their value for the children's physical and mental health development.

\subsection{The perplexity of parent-child book reading for preschool children in top classes}

\subsubsection{Parents' misunderstanding of picture book reading}

According to the above statistics, it can be concluded that, during the parent-child book reading, the majority of parents have made obvious positive changes in their understanding, using, participation, and attention, but there are still misunderstandings about the parent-child book reading. For one thing, parents' understanding of picture book reading is not comprehensive. Although their understanding of the nature of picture book reading is no longer limited to simple comic books, story books, or derivative books of cartoons, they will easily confuse when they facing other types of children books in the process of buying books. They emphasize the significance of letter education, but ignore the influence of picture books in art, science, health and other fields on children's physical and mental development.

For another, the tendency of "primary schools" is prominent. Top classes are an important stage for the transition of preschool children to primary school. Therefore, how to make preschool children transit from kindergarten to primary school smoothly is the most concerned topic for the parents of preschool children in top classes. However, due to the importance and particularity of the transition from kindergarten to primary school, parents often focus on the cultivation of intellectual development education at this stage. One of obvious performance is that parents pay special attention to the cultivation of words cognitive ability and reading habits of preschool children in top classes when reading picture books. Many parents regard picture books as an important literacy approach and tool in early reading.

\subsubsection{There is no clear basis for the selection of picture books}

As an important carrier in parent-child reading, selection basis of the picture books determines the quality of reading for preschool children. When choosing a picture book, parents should choose a picture book which is suitable for the age characteristics of preschool children in top classes. And this book can transit them from From picture reading to text reading, teach them how to think and understand the content of the story, and learn to experience the emotions of the characters in the story. Then, they should find a suitable picture book from the laws of education itself, and the reference of authoritative literature and policies in the field of preschool education Finally, according to children's interests, they should choose the picture books that children like.

\subsubsection{Scattered time and frequency of parents' participation in the reading of picture books}

The survey found that the vast majority of parents can participate in picture book reading activities with preschool children for 20-30 minutes each time. This duration is consistent with the reading duration of the preschool children in top classes, and is suitable for the age characteristics and reading habits of the preschool children in top classes. However, the overall time and frequency of parent-child book reading are scattered.

Firstly, the frequency of parents' participation in picture book reading is irregular. As parents are busy in work, it is impossible to guarantee the times and when to participate the picture book reading. This makes the picture book reading between the parents and children is unplanned, so it is hard to develop a reading habit. Secondly, parents usually use extracurricular time to participate in Parent-child reading. During the weekends when children are free, most children will participate in various interest-oriented classes and training courses. After the interest-oriented classes and training courses are over, the time of parent-child book reading will be shortened accordingly.

\subsubsection{Lack of correct picture book reading instruction method}

The parent-child book reading activity, as a two-way communication activity between parents and children, largely depends on the guidance methods adopted by parents in the process. Parents should focus on the preschool children, and provide effective instructions by mastering scientific parent-child reading skills, and actively seeking help from the outside environment. According to the author's survey, although many parents like to communicate with preschool children in picture book reading in the activities they participate in, they have failed to achieve effective parent-child book reading activities in specific methods. The most perplexing problem in the guidance from parents participating in picture book reading activities is to answer the children's questions first, and then how to correctly guide the children to read books. 


\subsection{Analysis of the path of parent-child book reading for preschool children in top classes}

With the changes of the time, picture books are widely concerned by parents due to their unique educational value and charm. However, in the process of parent-child book reading, parents also need to correctly understand the value of parent-child book reading, formulate a reasonable parent-child book reading plan and adopt a scientific picture book reading strategy to better guide children to read picture books.

\subsubsection{Correct understanding of the value of parent-child book reading}

Parents' understanding of the value of parent-child book reading helps parents guide preschool children to understand and explore the world more scientifically. Children in top classes aged 5-6 are in a stage of strong thirst for knowledge and curiosity. Therefore, picture book reading has not only intellectual development value but also other values for preschool children at this stage.

The value of logical thinking. In the picture books, the original text and the pictures that attract children's attention are complementary. Under the joint effect of the two, children can actively think about the internal connection between the picture and the text, and conjecture the development of the storyline. Those attempts will continuously improve their logical thinking ability. The value of artistic appreciation. From the perspective of aesthetics, reading novel pictures in picture books can help children appreciate aesthetic works, feel the impaction of color combination, and experience the composition designed by picture book authors. They can feel beauty, appreciate beauty, and express beauty when reading beautiful pictures. The value of emotional experience. After reading a picture book, preschool children can often perceive the emotional color conveyed by the story, and resonating it with similar emotional experienced in life.

\subsubsection{Master the selection basis for parent-child book reading}

The selection for parent-child book reading should according to the requirements of the Outline of Educational Guidance in Kindergartens (Trial), Early Learning and Development Guideline at 3-6 Years Old and other documents for the physical and mental health development of the preschool children in top classes, and should combine with the impact of the five major fields on children.

Firstly, we must choose picture books according to the laws of physical and mental development of preschool children in top classes. Preschool children in top classes are in the critical stage of pre-primary school. Cognition and language development have achieved new progress.
This is a critical stage for children to explore the world with curiosity Therefore, in the selection of picture books for preschool children at this stage, it can neither be too "childlike" nor "primary". But it is necessary to select suitable picture books according to the requirements of the Guidance and Outline. Also the selected books should be able to help the preschool children in top classes gradually transition from the pictures in the "bridge book" to the words. What's more, this kind of graphic and textual coordination should adapt to the physical and mental health characteristics of preschool children.

Secondly, we must follow the rules of preschool education. The great educationist Tao Xingzhi once proposed that "Life has educational meaning at all times" [7], and he established the theory of life education. Based on this, the selection of parent-child picture books should as close to life as possible. When choosing a book, it should be related to daily life as much as possible, such as clothing, food, housing, transportation, and so on. It will be better to choose things and situations that children are familiar with.

Finally, we must respect children's own interests and hobbies. As the picture book reading experience accumulates year after year, preschool children in top classes master more abilities to acquire knowledge rather than learn knowledge at the knowledge level, so preschool children will also be interested in learning knowledge. In the process of transition from kindergarten to primary school, we should help children understand the knowledge through topics that the preschool children in top classes are interested in.

\subsubsection{Reasonably formulate a parent-child book reading plan}

When parents plan their time, they should also make special plans for children's time. After formulating a common reading plan with preschool children, they should complete the reading task accurately within the time, and try to read every day. In addition, parents can also use scattered time, such as the odd hours before bed or after meals, to carry out picture book reading activities with preschool children. This behavior can create a good reading atmosphere for preschool children, and will be useful for cultivating the habit of completing the study plan on time. Besides, parents can create a warm and pleasant "reading corner" for preschool children at home, which is different from the schoolroom for adults. In the children's exclusive space, children can easily touch various picture books from the bookshelf and read at any time.

\subsubsection{Optimize guidance method for parent-child book reading}

Questioning method. The preschool children in the top class have the characteristics of analyzing the storyline, 
thinking positively, and having a strong curiosity. Therefore, parents can interact with children by asking questions when they participate in picture book reading. In addition, parents should pay attention to whether their language is instructive. They should cultivate the habit of children reading with questions.

Association method. According to Piaget's cognitive development theory, the thinking of children aged 5-6 is still based on concrete images, and the abstract logical thinking is sprouting. In the context of specific and detailed descriptions, parents can guide children to associate some plots or item descriptions with toys they are familiar with. This method can realize children's understanding of picture books and cultivate their imagination.

Extension method. After reading a picture book, parents can arrange other interest activities for preschool children in the reading plan. For example, the role play to the story characters of the book, or the arrangement of hand-made works. The reproduction of scene elements can promote the development of attention, language expression, aesthetic ability and other aspects of preschool children in top classes, and stimulate children's curiosity and creativity.

\section{CONCLUSION}

Parent-child book reading is an effective way of reading for family education. In the process of reading, the love interactions between parents and children are improved, and the feelings between parents and children are promoted. At the same time, parent-child book reading can cultivate the reading habits of preschool children in top classes. In summary, the parent-child book reading can exercise children's logical thinking, nurture their aesthetics, and cultivate good reading habits for children's future life and work.

\section{REFERENCES}

[1] C.Q. Kang, J.Y. Wu. Research on Strategies of Parent-child Picture Book Reading Promotion Service in Public Libraries-Based on the Status of Family Parent-child Picture Book Reading in Yuelu District, Changsha City. Library Work and Study, 2018(11): 116-123.

[2] S. Wang. On How Parents Treat and Guide Children to Read Picture Books Correctly. Education Teaching Forum, 2020(3) :377-378.

[3] Prepared by Basic Education Division of the Ministry of Education. Interpretation for the Outline of Educational Guidance in Kindergartens (Trial). Nanjing: Education Press, 2002:32.
[4] J.M, Li and X.X. Feng. Interpretation for Early Learning and Development Guideline at 3-6 Years Old. Beijing: People's Education Press, 2013:14,53.

[5] D. Nicholas, G. J. Melendez-Torres, L. Murray, F. Gardner, L. Hartford, P.J. Cooper. Shared Picture Book Reading Interventions for Child Language Development: A Systematic Review and Meta-Analysis Child Development, 2020, 91(2): 383-399.

[6] L. Cutler, R. Palkovitz. Fathers' Shared Book Reading Experiences: Common Behaviors, Frequency, Predictive Factors, and Developmental Outcomes. Marriage \& Family Review, 2020, 56(2): 144-173.

[7] Y.F. Sha. Family education should be centered on life-Reading and Thinking of the Guideline for National Family Education. Life Education, 2020, (6): 37-38. 